\title{
Low-level constitutional mosaicism of a de novoBRCA1 gene mutation
}

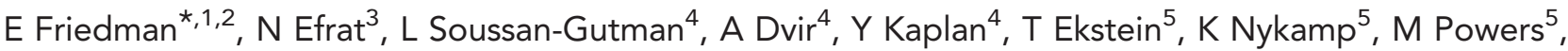 \\ M Rabideau ${ }^{5}$, J Sorenson ${ }^{5}$ and S Topper ${ }^{5}$ \\ ${ }^{1}$ The Susanne Levy Gertner Oncogenetics Unit, The Danek Gertner Institute of Human Genetics, Chaim Sheba Medical Center at \\ Tel-Hashomer, Tel-Aviv 5262100, Israel; ${ }^{2}$ Sackler School of Medicine, Tel-Aviv University, Tel-Aviv, 5262100, Israel; ${ }^{3}$ Department of \\ Oncology, Kaplan Medical Center, Rehovot, Israel; ${ }^{4}$ Oncotest-Teva, Teva Pharmeceuticals Industries, Petach Tikva 49510, Israel \\ and ${ }^{5}$ Invitae Corp., San Francisco, California 94107, USA
}

Background: Pathogenic BRCA1 mutations are usually inherited. Constitutional low-level BRCA1 mosaicism has never been reported.

Methods: Next-generation sequencing (NGS) of cancer gene panel of germline and tumour DNA in a patient with early onset, triple-negative breast cancer.

Results: Constitutional de novo mosaicism (5\%) for a pathogenic (c.1953dupG; p.Lys652Glufs*21) BRCA1mutation was detected in leukocytes, buccal tissue and normal breast tissue DNA, with $~ 50 \%$ mutation in tumorous breast tissue.

Conclusion: This is the first reported case of low-level, multiple tissue, constitutional mosaicism in BRCA1, and highlights the need to consider deep sequencing in affected individuals clinically suspected of having cancer predisposition whose tumours display a BRCA mutation.

Heterozygous germline mutations in the BRCA1 and BRCA2 (MIM $\left.{ }^{\star} 113705^{\star} 600185\right)$ genes detected in a subset of high-risk breast/ ovarian families are used clinically to objectively assess lifetime risks for developing these and other cancer types, and can have an impact on recommendations for early detection and risk-reducing surgeries (Petrucelli et al, 2010). DNA sequencing of the tumour tissue can be used to detect somatic mutations that may define therapeutic targets and refine treatment options (Ross et al, 2013; Ali et al, 2014). However, a third case is rarely considered somatic mutations in either gene acquired early in embryonic development, which establish a predisposition for disease but which are not detected by traditional sequencing technologies. The gold standard for detecting BRCA genes' sequence variants has long been Sanger sequencing, but recently next-generation sequencing (NGS) technologies have emerged as a highly accurate and efficient alternative (Feliubadalo et al, 2013; Kurian et al, 2014), with improved sensitivity for detection of mosaic events. Here we describe the occurrence of very low-level constitutional mosaicism of a pathogenic BRCA1 gene mutation and the possible implications of this novel finding.

\section{MATERIALS AND METHODS}

All mutation analyses were performed using an ethically approved protocol, subsequent to informed consent. NGS of 29 hereditary cancer genes in DNA extracted from the blood was performed at Invitae (San Francisco, CA, USA), a clinical laboratory improvement amendments-approved laboratory, using Invitae's Hereditary Cancer Panel (Kurian et al, 2014). The tested genes included $A P C$, ATM, BMPR1A, BRCA1, BRCA2, BRIP1, CDH1, CDK4, CDKN2A, CHEK2, EPCAM, MEN1, MET, MLH1, MSH2, MSH6, MUTYH, NBN, PALB2, PALLD, PMS2, PTCH1, PTEN, RAD51C, RET, SMAD4, STK11, TP53 and VHL. Targeted genes were captured from genomic DNA extracted from whole blood using SureSelect

*Correspondence: Professor E Friedman; E-mail: eitan.friedman@sheba.health.gov.il or eitan211@netvision.net.il

Received 26 November 2014; revised 24 December 2014; accepted 30 December 2014; published online 29 January 2015

(c) 2015 Cancer Research UK. All rights reserved 0007-0920/15 
probes (Agilent, Santa Clara, CA, USA) or xGen Lockdown probes (Integrated DNA Technologies, Coral, IL, USA). Next-generation DNA sequencing (NGS) was carried out on the MiSeq or HiSeq 2500 platform (Illumina, San Diego, CA, USA) to a minimum of $50 \times$ required to report an alteration at any site. Sequence reads were aligned against the reference human genome sequence and sequence variants (single-nucleotide changes, insertions and deletions), as well as copy number variants (deletions and duplications), and were called from the NGS data. Sequence analysis was performed for all targeted genes and copy number analysis was performed for all genes except CHEK2, PALLD and MET. Procedures were implemented to ensure adequate NGS coverage and quality over the targeted genes, to detect sample swaps and to detect sample cross-contamination.

Somatic analysis was performed using a test based on massively parallel DNA sequencing across 287 cancer-related genes from routine formalin-fixed and paraffin-embedded clinical specimens, both from the breast tumour and the healthy breast tissue (Foundation Medicine, Cambridge, MA, USA). Reference samples of pooled cell lines that model key determinants of accuracy, including mutant allele frequency, indel length and amplitude of copy change. The percentage of reads with the alteration was communicated by e-mail.

\section{RESULTS}

Case report. The proband, a Jewish woman of mixed Ashkenazi (paternal) and Bulgarian (maternal) origin was diagnosed with a large $(8 \times 10 \mathrm{~cm})$, triple-negative, high-grade, high ki67 (60\%), invasive unilateral breast cancer at age 43 years. Her family history pertaining to cancer included a daughter with acute lymphatic leukemia at age 18 months, a brother with a CNS tumour at age 45 years, a father with a malignant CNS tumour at age 58 years, a maternal grandfather with a malignant tumour of unknown pathological features in his $70 \mathrm{~s}$ and two of this maternal grandfather's sisters who were diagnosed with breast cancer at unknown ages. The patient was treated with standard neoadjuvant chemotherapy consisting of four cycles of doxorubicin/cyclophosphamide and 12 weekly cycles of paclitaxel and carboplatin. Neoadjuvant chemotherapy was followed by bilateral mastectomy (therapeutic mastectomy and contralateral, risk-reducing mastectomy) and reconstruction. At surgery, residual tumour was evident and was followed by chest and lymphatic region irradiation. Pathologically confirmed, triple-negative breast cancer recurred in the reconstructed breast and in the contralateral reconstructed breast 3 months after radiotherapy. Systemic treatment with bevacizumab and capecitabine was followed by gemcitabine/cisplatinum with minimal, short lasting response. The patient died 15 months after initial diagnosis.

Genetic analyses. Next-generation DNA sequencing of 29 hereditary cancer genes in DNA extracted from the blood identified a pathogenic BRCA1 mutation in $5 \%$ of reads $(\sim 3000 \times$ at this locus): c.1953dupG (NM_007294.3), which leads to a lysine to glutamine alteration in codon 652 and a premature stop codon 21 amino acids downstream (p.Lys652Glufs ${ }^{\star} 21$ ). No other pathogenic mutations were detected in any of the other analysed cancer susceptibility genes. A second independent blood draw and a buccal swab were also tested at Invitae (and blood draw 1 was tested again, to establish technical reproducibility) and a mosaic signal of $4.9 \%-6.8 \%$ was reproducibly detected in all samples. Earlier, Sanger sequencing of BRCA1 and BRCA2 in DNA extracted from peripheral blood, performed as part of the routine clinical workup at a different commercial lab, had not detected this mutation. However, careful evaluation of this locus in confirmatory Sanger sequence at Invitae did demonstrate the presence of a small peak (Figure 1). Interestingly, tumour tissue from the right breast was sequenced by a commercially available somatic NGS assay (Frampton et al, 2013) and the same mutation, c.1943dupG, was detected in $47 \%$ of sequence reads $(>500 \times$ coverage). The mutation was also detected in $5 \%$ of reads derived from normal tissue from the histopathologically normal left breast. Together, these results confirm that this individual is a constitutional mosaic for this mutation (Table 1). Analysis of the maternal peripheral blood DNA using the Invitae deep-sequencing platform demonstrated the absence of this mutation.

Notably, for normal tissue samples, the percentage of cells that are heterozygous for the mutation is twice the percentage of sequence reads that carry the insertion. For tumour cells, the observed percentage of affected sequence reads depends on the homogeneity of the biopsy and may be confounded by acquired deletions on the opposite allele; thus, the percentage of cells carrying this mutation on one chromosome cannot be accurately estimated.

The c.1953dupG BRCA1 mutation is $129 \mathrm{bp}$ away from a common SNP (c.2082C > T; rs1799949), which is also absent in the maternal DNA sample, indicating that the SNP identifies the paternally inherited allele. An analysis of reads spanning both positions (c.1953 and c.2082) identifies sequence reads containing both variants, indicating that the c.1953dupG mutation is in cis with the c.2082 variant and is on the paternal allele. This analysis also identifies the presence of reads containing the c. 2082 variant and not the c.1953dupG mutation, a finding indicating that the c.1953dupG mutation was not inherited, but was acquired post fertilisation.

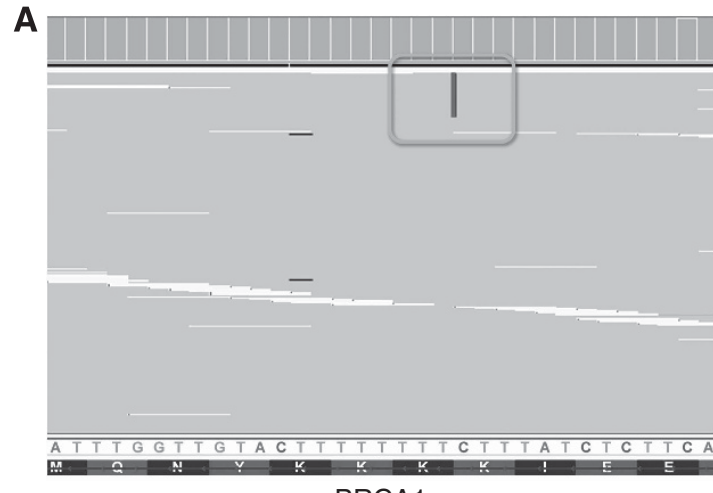

BRCA1

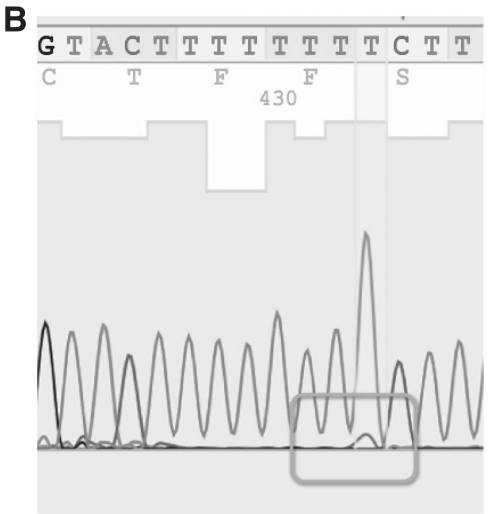

Figure 1. Data supporting mosaic mutation. (A) A visualisation of NGS data from blood draw 1, extraction 1. Reads carrying thec.1953dupG insertion are indicated with the purple line. (B) Sanger-sequence data confirming the presence of the c.1953dupG mutation in a portion of cells. The signal is almost indistinguishable from background noise. Reference sequence indicates the positive strand. 
Table 1. Mutational load in different tissues

\begin{tabular}{|c|c|c|c|c|}
\hline Tissue & $\begin{array}{l}\text { Reads indicating } \\
\text { insertion }\end{array}$ & $\begin{array}{l}\text { Total depth at this } \\
\text { position }\end{array}$ & $\begin{array}{c}\% \text { Reads carrying the } \\
\text { insertion }\end{array}$ & $\begin{array}{c}\% \text { Heterozygous } \\
\text { cells }\end{array}$ \\
\hline Blood (draw 1, extraction 1) & 164 & 3307 & 5.0 & 9.9 \\
\hline Blood (draw 1, extraction 2) & 143 & 2889 & 4.9 & 9.9 \\
\hline Blood (draw 2) & 127 & 2460 & 5.2 & 10.3 \\
\hline Buccal swab & 149 & 2207 & 6.8 & 13.5 \\
\hline Normal breast tissue & - & - & 5.0 & 10.0 \\
\hline Breast tumour & - & - & 47.0 & Uncertain \\
\hline
\end{tabular}

\section{DISCUSSION}

This case represents the first report of a very low-level constitutional mosaic pathogenic BRCA1 mutation. NGS studies of DNA extracted from three normal tissues (blood, buccal swab and normal breast tissue) detected the pathogenic variant in $\sim 5 \%$ of reads, while sequencing of tumour tissue detected the pathogenic variant in $\sim 50 \%$ of reads. These data confirm that this individual is a constitutional mosaic for this mutation and suggest strongly that this mutation is driving tumour development in this individual. Alternative explanations for this finding (circulating tumour cells, technical error and somatic mosaicism in the tumour alone) have been ruled out by identifying the same sequence change in two independent blood samples, in buccal tissue and in non-cancerous breast tissue at approximately the same detection levels. In previous reports of somatic BRCA1 mutations, only tumour cells harboured the mutant allele (Takahashi et al, 1995; Welcsh and King, 2001; Janatova et al, 2005; Zhang et al, 2012).

The mutation in this individual had been missed in a clinical, Sanger-based sequencing assay of BRCA1 and BRCA2 of DNA extracted from the blood, as Sanger sequencing, in general, cannot reliably detect a mutation present at a load of $<20 \%$ (Rohlin et al, 2009).This case illustrates the need to possibly consider genetic testing by applying deep-sequencing methodology in individuals whose clinical features are suggestive of a genetic predisposition, whose tumours show a $B R C A$ mutation that cannot be confirmed with standard Sanger sequencing. In this case, the genetic predisposition was highlighted by an early age of onset, a triplenegative tumour (Gonzalez-Angulo et al, 2011) and breast cancer diagnosed in the contralateral breast within a few months after the initial diagnosis. Notably, family history is non-contributory, as the closest relatives with $B R C A 1$-related tumours are third-degree relatives on the maternal side (the maternal grandfather's sisters) and the mother does not carry the mutation, and the mutant allele is paternally inherited, although the family history on the paternal side is not consistent with a BRCA1 phenotype.

A few cases of de novo constitutional BRCA1 or BRCA2 have previously been described, but most were detected in a heterozygous form in constitutional DNA and were not mosaic (Tesoriero et al, 1999; Robson et al, 2002; Hansen et al 2008; Edwards et al, 2009; Marshall et al, 2009; Garcia-Casado et al, 2011; Kwong et al, 2011; Zhang et al, 2011) or detected at a high frequency of $>70 \%$ of cells (Delon et al, 2013). The per cent of hereditary breast ovarian cancer cases that can be attributed to low-level constitutional mosaicism is not known at this time.

This case demonstrates conclusively that low-level constitutional mosaicism for pathogenic mutations in BRCA1 can be a cause of early-onset breast cancer, and the consistency of the load across tissue types suggests that this event occurred early in embryonic development. This notion is further supported by the lack of the same mutation in maternal constitutional DNA using deep sequencing. This case may offer new insights into clinical decision-making regarding genetic testing for breast cancer cases, and further expansion to explore the extent of the phenomenon is warranted. It also seems that NGS sequencing should be considered and discussed with affected individuals whose tumours display a BRCA mutation that cannot be demonstrated using Sanger sequencing. It seems that constitutional mosaics for a pathogenic mutation in BRCA1 similar to constitutional heterozygous mutation carriers should be counselled as to their own risk for contralateral breast cancer, ovarian cancer and cancer risks for their offspring.

\section{ACKNOWLEDGEMENTS}

We thank the patient and the patient's family, as well as everyone who performed the genetic testing and analysed the data.

\section{CONFLICT OF INTEREST}

TE, KN, MP, MR, JS and ST are employed by the InVitae Corporation; LS-G, AD and YK are all employed by OncotestTeva, the distributor of InVitae in Israel. EF and NE declare no conflict of interest.

\section{REFERENCES}

Ali SM, Alpaugh RK, Buell JK, Stephens PJ, Yu JQ, Wu H, Hiemstra CN, Miller VA, Lipson D, Palmer GA, Ross JS, Cristofanilli M (2014) Antitumor response of an ERBB2 amplified inflammatory breast carcinoma with EGFR mutation to the EGFR-TKI erlotinib. Clin Breast Cancer 14(1): e14-e16.

Delon I, Taylor A, Molenda A, Drummond J, Oakhill K, Girling A, Liu H, Whittaker J, Treacy R, Tischkowitz M (2013) A germline mosaic BRCA1 exon deletion in a woman with bilateral basal-like breast cancer. Clin Genet 84(3): 297-299.

Edwards E, Yearwood C, Sillibourne J, Baralle D, Eccles D (2009) Identification of a de novo BRCA1 mutation in a woman with early onset bilateral breast cancer. Fam Cancer 8(4): 479-482.

Feliubadalo L, Lopez-Doriga A, Castellsague E, del Valle J, Menendez M, Tornero E, Montes E, Cuesta R, Gómez C, Campos O, Pineda M, González S, Moreno V, Brunet J, Blanco I, Serra E, Capellá G, Lázaro C (2013) Next-generation sequencing meets genetic diagnostics: development of a comprehensive workflow for the analysis of BRCA1 and BRCA2 genes. Eur J Hum Genet 21(8): 864-870.

Frampton GM, Fichtenholtz A, Otto GA, Wang K, Downing SR, He J, Schnall-Levin M, White J, Sanford EM, An P, Sun J, Juhn F, Brennan K, Iwanik K, Maillet A, Buell J, White E, Zhao M, Balasubramanian S, Terzic S, Richards T, Banning V, Garcia L, Mahoney K, Zwirko Z, Donahue A, Beltran H, Mosquera JM, Rubin MA, Dogan S, Hedvat CV, Berger MF, Pusztai L, Lechner M, Boshoff C, Jarosz M, Vietz C, Parker A, Miller VA, Ross JS, Curran J, Cronin MT, Stephens PJ, Lipson D, Yelensky R (2013) Development and validation of a clinical cancer genomic profiling test based on massively parallel DNA sequencing. Nat Biotechnol 31(11): 1023-1031. 
Garcia-Casado Z, Romero I, Fernandez-Serra A, Rubio L, Llopis F, Garcia A, Llombart P, Lopez-Guerrero JA (2011) A de novo complete BRCA1 gene deletion identified in a Spanish woman with early bilateral breast cancer. BMC Med Genet 12: 134-143.

Gonzalez-Angulo AM, Timms KM, Liu S, Chen H, Litton JK, Potter J, Lanchbury JS, Stemke-Hale K, Hennessy BT, Arun BK, Hortobagyi GN, Do KA, Mills GB, Meric-Bernstam F (2011) Incidence and outcome of BRCA mutations in unselected patients with triple receptor-negative breast cancer. Clin Cancer Res 17(5): 1082-1089.

Hansen TV, Bisgaard ML, Jonson L, Albrechtsen A, Filtenborg-Barnkob B, Eiberg H, Ejlertsen B, Nielsen FC (2008) Novel de novo BRCA2 mutation in a patient with a family history of breast cancer. BMC Med Genet $\mathbf{9}$ : $58-67$.

Janatova M, Zikan M, Dundr P, Matous B, Pohlreich P (2005) Novel somatic mutations in the BRCAl gene in sporadic breast tumors. Hum Mutat 25(3): 319.

Kurian AW, Hare EE, Mills MA, Kingham KE, McPherson L, Whittemore AS, McGuire V, Ladabaum U, Kobayashi Y, Lincoln SE, Cargill M, Ford JM (2014) Clinical evaluation of a multiple-gene sequencing panel for hereditary cancer risk assessment. J Clin Oncol 32(19): 2001-2009.

Kwong A, Ng EK, Tang EY, Wong CL, Law FB, Leung CP, Chan A, Cheung MT, To MY, Ma ES, West DW, Ford JM (2011) A novel de novo BRCA1 mutation in a Chinese woman with early onset breast cancer. Fam Cancer 10(2): 233-237.

Marshall M, Solomon S, Lawrence Wickerham D (2009) Case report: de novo BRCA2 gene mutation in a 35 -year-old woman with breast cancer. Clin Genet 76(5): 427-430.

Petrucelli N, Daly MB, Feldman GL (2010) Hereditary breast and ovarian cancer due to mutations in BRCA1 and BRCA2. Genet Med 12(5): 245-259.

Robson M, Scheuer L, Nafa K, Ellis N, Offit K (2002) Unique de novo mutation of BRCA2 in a woman with early onset breast cancer. $J$ Med Genet 39(2): 126-128.
Rohlin A, Wernersson J, Engwall Y, Wiklund L, Bjork J, Nordling M (2009) Parallel sequencing used in detection of mosaic mutations: comparison with four diagnostic DNA screening techniques. Hum Mutat 30(6): $1012-1020$.

Ross JS, Wang K, Sheehan CE, Boguniewicz AB, Otto G, Downing SR, Sun J, He J, Curran JA, Ali S, Yelensky R, Lipson D, Palmer G, Miller VA, Stephens PJ (2013) Relapsed classic E-cadherin (CDH1)-mutated invasive lobular breast cancer shows a high frequency of HER2 (ERBB2) gene mutations. Clin Cancer Res 19(10): 2668-2676.

Takahashi H, Behbakht K, McGovern PE, Chiu HC, Couch FJ, Weber BL, Friedman LS, King MC, Furusato M, LiVolsi VA, Menzin AW, Liu PC, Benjamin I, Morgan MA, King SA, Rebane BA, Cardonick A, Mikuta JJ, Rubin SC, Boyd J (1995) Mutation analysis of the BRCA1 gene in ovarian cancers. Cancer Res 55(14): 2998-3002.

Tesoriero A, Andersen C, Southey M, Somers G, McKay M, Armes J, McCredie M, Giles G, Hopper JL, Venter D (1999) De novo BRCA1 mutation in a patient with breast cancer and an inherited BRCA2 mutation. Am J Hum Genet 65(2): 567-569.

Welcsh PL, King MC (2001) BRCA1 and BRCA2 and the genetics of breast and ovarian cancer. Hum Mol Genet 10(7): 705-713.

Zhang L, Fleischut MH, Kohut K, Spencer S, Wong K, Stadler ZK, Kauff ND, Offit K, Robson ME (2011) Assessment of the prevalence of de novo mutations in the BRCA1 and BRCA2 genes. Clin Genet 80(1): 97-98.

Zhang M, Xu Y, Ouyang T, Li J, Wang T, Fan Z, Lin B, Xie Y (2012) Somatic mutations in the BRCA1 gene in chinese women with sporadic breast cancer. Breast Cancer Res Treat 132(1): 335-340.

This work is published under the standard license to publish agreement. After 12 months the work will become freely available and the license terms will switch to a Creative Commons AttributionNonCommercial-Share Alike 4.0 Unported License. 